\title{
AMBIENTE ESCOLAR, ORIENTAÇÕES SEXUAIS E AS NOVAS IDENTIDADES DE GÊNERO
}

\author{
Lorena Carlos Aiala ${ }^{1}$ \\ Vivian Ferreira Morais de Carvalho ${ }^{2}$
}

\section{INTRODUÇÃO}

A discussão acerca da diversidade sexual e de gênero é necessária nas escolas. Isso porque, atos violentos praticados contra indivíduos - sejam físicos, verbais ou psicológicos- estão mais frequentes a cada dia. A homofobia na sociedade brasileira é evidente, mas ao mesmo tempo, velada e pode ser compreendida como atos violentos praticados contra um ou mais indivíduos - sejam eles físicos, verbais ou psicológicos - e que sobrevive seja nas palavras não ditas, seja nas ditas brincadeiras ou piadas.

$\mathrm{Na}$ escola, essas práticas não são distintas, ou seja, esta instituição que, na teoria educa e orienta, se silencia diante de situações de enfrentamentos e acaba por reforçar 0 preconceito àquele indivíduo que não se enquadra na heteronormatividade. Para Junqueira (2007), a escola abre espaço para ações educacionais que promovam a equidade de gênero, a inclusão social e a constituição de uma cidadania para todas(os), combatendo a homofobia. Nesse sentido, o presente trabalho tem por objetivo identificar se as "novas" identidades sexuais e de gênero podem desencadear enfrentamentos didáticos-disciplinares e analisar a percepção de alunos e professores em relação a enfrentamentos vivenciados dentro e fora de sala de aula em uma Escola Estadual Z situada em Belo Horizonte / Minas Gerais.

\section{QUADRO TEÓRICO}

\footnotetext{
${ }^{1}$ Graduanda em Ciências Sociais pela Pontifícia Universidade Católica de Minas Gerais, lorena.aiala@hotmail.com

${ }^{2}$ Graduanda em Ciências Sociais pela Pontifícia Universidade Católica de Minas Gerais, vivian.carvalhoo@hotmail.com
} 
A literatura mostra que as configurações de boa parte das escolas brasileiras não contemplam o diálogo de maneira geral (DE JESUS, 2015; LIONÇO; DINIZ, 2008; LUCION, 2011). Quando se trata da diversidade sexual, o índice deste elemento fundamental - diálogo - praticamente desaparece.

Em relação a assuntos de diversidade sexual, percebe-se que o ambiente escolar é silenciador, pois constitui a heterossexualidade como sendo uma única forma de expressão sexual e obrigatória e essa exigência de se manter nos padrões definidos é que gera a prática discriminatória (DE JESUS, 2015). A escola e o ambiente escolar não possuem contribuições adequadas para lidar com esse tipo de assunto, e a maneira como ela se organiza não permite o aparecimento da diversidade de identidades e apesar de não poder dar contribuições de fato, o ambiente escolar constitui uma parte importante na vida dos estudantes. Na escola a homofobia é revelada por meio de agressões físicas e verbais e gera conflitos que vão desde debates até protestos.

\section{METODOLOGIA}

A metodologia para a realização desta pesquisa foi qualitativa, com utilização de técnicas observação participante e entrevistas. A escolha pela Escola Estadual Z em Belo Horizonte se deu pelo fato de sermos bolsistas do PIBID na mesma. Além disso, a convivência com os alunos nos fez perceber a necessidade de estabelecer um diálogo sobre identidades sexuais e homofobia - vivenciada por vários alunos. Por outro lado, a escola - equipe pedagógica, direção - se omitiam. As entrevistas aconteceram no final do mês de outubro e início de novembro. Desta maneira, foram realizadas nove entrevistas, sendo seis alunos - três alunas e três alunos - e três professores - história, filosofia e sociologia. Quatro dos seis alunos cursam $01^{\circ}$ ano do ensino médio e os outros dois, o $2^{\circ}$ ano. As idades variam entre 15 e 19 anos. O critério de seleção dos alunos entrevistados baseou-se na orientação sexual não correspondente a heteronormatividade; já o critério dos professores foi a disponibilidade dos mesmos para a participação da pesquisa, uma vez que entendemos que quaisquer disciplina contemplam discussões sobre a diversidade sexual e de gênero. Por fim, a observação participante aconteceu ao longo do $2^{\circ}$ semestre de 2015 , desde agosto, até o final de novembro. 


\section{ANÁLISE DE RESULTADOS}

Para as análises das entrevistas, as perguntas contidas no roteiro foram categorizadas em três eixos: Espaços de Fala, Disciplina e Sexualidade e Diversidade de Identidade sexual e de Gênero. No primeiro bloco, a pesquisa revelou que com os amigos os alunos têm maior liberdade para conversar sobre suas relações afetivas. Geralmente, fala-se sobre tudo, sem restrições, portanto há confiabilidade no círculo de amizade. Em relação ao diálogo acerca das relações afetivas com a família - somente a figura materna apareceu em todas as entrevistas. Esse espaço é restrito, às vezes, pela ausência da conformidade acerca da orientação sexual do aluno, pelo desconforto de falar sobre relacionamentos homoafetivos, ou até mesmo pelo respeito que se tem com a mãe. Percebemos que, mesmo nos casos em que a mãe se porta de forma "tolerante" tentando se aproximar e orientar, os alunos afirmam que preferem não aprofundar neste assunto, pois há uma restrição dos assuntos discutidos seja por medo ou vergonha devido ao tabu existente acerca do tema sexualidade. Sobre isso, um dos entrevistados relatou: "lá em casa é bem normal, assim, minha mãe tenta puxar conversa, querer perguntar, mas assim, eu acho que eu que não dou muita abertura pra ela, quando eu quero falar eu falo."

Dois professores participantes do estudo são das áreas de filosofia e sociologia e trabalham há mais tempo na escola. Já a professora de história trabalha há aproximadamente dois meses. O professor de filosofia acredita que, encontrar um aluno que se identifica com uma nova identidade sexual é um desafio maior para os outros alunos do que para ele. A professora de sociologia diz não ter dificuldade ao se deparar em sala de aula com alunos que não se enquadram na heteronormatividade, para ela não faz diferença o(a) aluno(a) ser homossexual. A professora de história afirmou que ainda não conhece todos os alunos e às vezes sabe da identidade sexual e/ou de gênero por relatos de outros alunos dentro da sala de aula. De maneira geral, os professores percebem a necessidade de diálogo acerca da diversidade sexual, independente de ter ou não um aluno que se enquadra na heteronormatividade.

Os professores de sociologia e filosofia, coincidentemente, relatam 0 exemplo do mesmo aluno ao falar como a sexualidade interfere na disciplina. Segundo eles, este aluno tinha necessidade de intervir, a ponto de atrapalhar o 
andamento das atividades. Desta maneira, ambos procuravam métodos para "encaixar" as intervenções do mesmo, de forma que viesse a contribuir. Para a professora de sociologia, as diversas identidades sexuais interferem na disciplina de forma positiva, uma vez que, através de uma queixa de um aluno, se produziu um evento na escola para conversar sobre o tema.

O segundo bloco de entrevistas teve como foco a vivência dos alunos representantes do movimento LGBT. Neste momento das entrevistas houve relatos sobre como a escola se porta diante de suas identidades sexuais e de gênero. Um dos entrevistados, afirmou que até mesmo nas coisas mais banais, como por exemplo, dividir a fila em meninos e meninas, ele se sente reprimido e constrangido. Outra entrevistada relatou que a professora de uma disciplina olha para ela de forma diferente ao falar da homossexualidade, e ainda afirma que "o mundo está perdido". O entrevistado 4 diz que, as piadinhas são frequentes, mas não direciona este problema para a coordenação; a fala do mesmo se contradiz no momento em que relata que, a escola toma atitudes com relação à diversidade sexual, porque há um professor homossexual na escola. A entrevistada 5 acredita que, "gays" sofrem mais do que as "lésbicas", pois são alvo de piadinhas. O entrevistado 6, relata uma confusão com uma professora, pois esta disse que ele estava "dando em cima" dos colegas em sala de aula, no final das contas, a coordenação conversou com a professora e com o aluno, e nada mais foi falado sobre este assunto.

Quando perguntados sobre a falta de conhecimento gerar preconceito/discriminação a professora de sociologia acredita que, a ausência de conhecimento acarreta no preconceito, entretanto, ao comparar redações produzidas por alunos antes e depois do conteúdo apresentado, não só em sala de aula, mas também com palestra, percebeu-se que, os alunos continuavam com o mesmo posicionamento. A professora ainda afirma que, os mesmos alunos homofóbicos, são racistas, e conclui que é uma cultura familiar, mas que cabe a escola "desestabilizar" o conhecimento do indivíduo, para que este construa a própria concepção. O professor de filosofia afirma que, por mais absurdo que possa parecer, cabe ao professor desconstruir atitudes discriminatórias, mas enfatiza que, ter somente uma aula por semana é algo que dificulta o desdobramento das discussões. Já a professora de história, apesar do pouco contato com os alunos, acredita que o professor deve orientar e discutir acerca do tema. 
No último bloco, pretendeu-se verificar o quão a escola está preparada para lidar com as "novas" identidades sexuais e de gênero. Através dos relatos dos alunos entrevistados notou-se que, há silenciamento da equipe pedagógica, e despreparo ao tratar do assunto. O despreparo da equipe pedagógica é a justificativa dos alunos de não relatar para a mesma, os acontecimentos homofóbicos vivenciados. As disciplinas que abordam o tema diversidade sexual, de acordo com os alunos são filosofia, sociologia, português, história, biologia e artes as disciplinas não foram citadas por todos. Além disso, quando perguntados sobre a importância da escola tratar deste tema, as respostas foram unânimes, no sentido de que, a escola deve abordar este tema:

\begin{abstract}
"É uma forma de começar uma mudança na sociedade, porque a galera frequenta a escola e nessa escola não se trata do assunto. Como elas vão se preparar pro mundo lá fora? Ele pode trabalhar com um gay, pode trabalhar com um transexual, pode trabalhar com uma pessoa diferente que ele nunca ouviu falar daquilo, e na escola seria uma forma de começar essa mudança, os professores tratando deste assunto como se fosse uma coisa que tá no dia a dia, uma coisa respeitosa, faria a diferença, com certeza." (Entrevistado 2, trecho de entrevista).
\end{abstract}

O professor de filosofia acredita que, se o aluno vivenciar algum tipo de enfrentamento relacionado à identidade sexual, o último lugar que este deve procurar é a equipe pedagógica, não só pela falta de preparo, mas também por serem preconceituosos e despreparados de forma geral; este afirma que cabe sim a escola, colaborar, contribuir para o desenvolvimento dos alunos, não só intelectual, mas também humano. Para professora de sociologia, os livros didáticos possuem ótima bibliografia, porém, o fato de ter somente uma aula por semana impossibilita 0 uso deste com regularidade. Além disso, a professora acredita no dever do professor, sobretudo da escola, de tratar deste assunto, pois a cada dia a necessidade se mostra mais evidente.

O estudo evidenciou que, dentre os motivos para enfrentamentos didáticos-disciplinares, as "novas" identidades sexuais e de gênero é um dos motivos para este acontecimento. É perceptível a necessidade de diálogo, entre alunos e professores. Percebe-se que a equipe pedagógica - supervisão e direção não está preparada para mediar situações decorrentes da homofobia e devido seu silenciamento, acaba por reforçar este preconceito. Os professores acreditam que, seja dever falar sobre as diversidades, - não só sexual - pois ressaltam que, o mesmo aluno homofóbico é racista, mas reconhecem a ausência de pensamento 
crítico, - da própria categoria - que dificulta estabelecer diálogo. Por causa disso, os alunos convivem com piadas, brincadeiras e o silêncio devastador, mas não se organizam para encontrar um meio para amenizar a homofobia vivenciada dentro da instituição escolar.

A partir do estudo realizado, percebeu-se a falta de preparo da equipe pedagógica - supervisão e direção - da escola para lidar com os enfrentamentos didático-disciplinares vivenciados pelas novas identidades sexuais e de gênero, devido ao desinteresse e ao padrão da heteronormatividade ainda arraigada na cultura brasileira e principalmente num local como a escola, que muitas vezes reproduz o preconceito. Além disso, percebeu-se também a necessidade da escola tratar do tema diversidade sexual e de gênero, sabendo conduzir possíveis casos de enfrentamentos didático-disciplinares.

Um dos achados exploratórios mais significativos percebidos durante as entrevistas foram as diferenças de discurso entre meninos e meninas referentes às percepções dos mesmos acerca dos enfrentamentos sofridos por eles no ambiente escolar. As meninas se apresentaram mais observadoras e apontaram casos sofridos pelos meninos, enquanto que os mesmos afirmavam ser algo "normal" no cotidiano da escola e ainda afirmavam que não sofriam enfrentamentos.

\section{REFERÊNCIAS}

DE JESUS, C.C. Homossexualidade nas Escolas: as Concepções de Educadores acerca da Homofobia no Contexto Escolar. Boletim Historiar, n.08, mar./abr. 2015, p. 19-32.

JUNQUEIRA, R. D. O reconhecimento da diversidade sexual e a problematização da homofobia no contexto escolar. In: SEMINÁRIO CORPO, GÊNERO E SEXUALIDADE: DISCUTINDO PRÁTICAS EDUCATIVAS, 3., 2007. Anais... Rio Grande, RS: Ed. da FURG, 2007.

LIONÇO, T., DINIZ, D. Homofobia, Silêncio e Naturalização: por uma narrativa da diversidade sexual. Rev.Psicologia Política., v. 8, n. 16, p. 307-324, jul/dez 2008,

LUCION, C. Homofobia na Escola Pública. Paraná, 2008. Disponível em:

<http://www.diaadiaeducacao.pr.gov.br/portals/pde/arquivos/981-4.pdf> Acesso em: 30 nov. 2015. 